.

\title{
Resiliência da mobilidade urbana: uma proposta conceitual e de sistematização
}

\author{
Vicente Aprigliano Fernandes ${ }^{1}$, Rainer Rothfuss ${ }^{2}$, Volker Hochschild ${ }^{3}$, William Ribeiro da Silva ${ }^{4}$ \\ Marcio Peixoto de Sequeira Santos ${ }^{4}$
}

1Departamento de Geografia, Eberhard Karls Universität Tübingen, vicente.geo.ufrj@gmail.com

2Departamento de Geografia, Eberhard Karls Universität Tübingen, rainer.rothfuss@uni-tuebingen.de

3Departamento de Geografia, Eberhard Karls Universität Tübingen, volker.hochschild@uni-tuebingen.de ${ }^{4}$ Departamento de Geografia, Universidade Federal do Rio de Janeiro (UFRJ),williamribeiro@hotmail.com

5Programa de Engenharia de Transportes, COPPE/UFRJ, marcio@pet.coppe.ufrj.br

\section{Recebido:}

17 de fevereiro de 2016

Aceito para publicação:

20 de fevereiro de 2017

Publicado:

30 de dezembro de 2017

Editor de área:

Cira Souza Pitombo

\section{Palavras-chaves:}

Resiliência,

Mobilidade,

Combustível Fóssil.

\section{Keywords:}

Resilience,

Mobility,

Fossil Fuels.

DOI:10.14295/transportes.v25i4.1079

OPEN ACCESS

\section{RESUMO}

Estudos voltados para mobilidade sustentável vêm crescendo desde o final do século XX, e desde então os trabalhos empíricos e teóricos são crescentes neste âmbito. Este trabalho introduz um tema que ainda está pouco desenvolvido dentro da área de transportes, que é a preocupação com a vulnerabilidade da mobilidade urbana, frente a ameaças repentinas e espontâneas, em termos de recursos naturais, no âmbito da disponibilidade em si e a volatilidade econômica destas commodities - em evidência o petróleo. Desta forma, este artigo contribui com uma revisão histórica da relação entre o setor dos transportes urbanos e as fontes de energia. Além disso, apresenta-se de forma incipiente uma proposta de conceituação e sistematização da resiliência da mobilidade urbana.

\begin{abstract}
Studies focused on sustainable mobility have been growing since the late twentieth century, and since then the empirical and theoretical contributions are increasing in this scope. However, this work introduces a topic that has been little developed in the transportation area yet, which is the aspect of the vulnerability of urban mobility, by potentially facing sudden and spontaneous threats, in terms of natural resources, concerning availability itself and the economic volatility of these commodities (e.g. oil, natural gas, etc.). Thus, this article contributes with a historical review of the relationship between transport and energy sources. Besides that, it also contributes with an incipient framework of the urban mobility resilience concept.
\end{abstract}

\section{INTRODUÇÃO}

Em que direção as cidades dos países desenvolvidos e em desenvolvimento estão caminhando? A população urbana do globo já ultrapassou os $50 \%$ da população mundial, e de acordo com as Nações Unidas (2015), este percentual pode alcançar $66 \%$ até 2050 . Por conta deste prospecto, espera-se que soluções eficientes sejam desenvolvidas para aprimorar aspectos sociais, econômicos e ambientais, frente ao aumento dos problemas urbanos que ameaçam cidades em toda parte do planeta.

Por conta das crescentes preocupações com os impactos da urbanização na disponibilidade de recursos naturais, nas mudanças climáticas e qualidade de vida, este artigo busca focar no tema da mobilidade urbana, e sua ligação com questões relacionadas aos combustíveis fósseis. Apesar de existir um esforço para aprimorar o setor de transporte nas cidades, ainda há uma crescente demanda na melhora da mobilidade urbana e na redução dos impactos ambientais gerados por este setor. 
Aqui a mobilidade urbana é tratada sob a perspectiva da resiliência, com o objetivo de compreender a mobilidade urbana frente a ameaças, como aumento inesperado do preço do combustível ou redução da disponibilidade de recursos energéticos, como petróleo e gás. É compreendido que este tipo de ameaça para as nossas cidades e atuais sistemas de transporte pode ser gerado por motivos antropogênicos ou naturais.

O conceito de resiliência utilizado neste artigo consiste em uma visão sócio-ecológica (Folke et al., 2010), envolvendo características de interrupção de uma perturbação, reorganização, sustentação e desenvolvimento do ambiente e da qualidade de vida de seus habitantes. Com base nestas características, este conceito é aplicado em estudos que buscam compreender a capacidade de um sistema de persistir, adaptar e se transformar, quando exposto a ameaças internas ou externas. E, além disso, é um conceito adequado para a avaliação de sistemas complexos, em que existe interações dinâmicas entre diferentes escalas e fatores, que é o caso do espaço urbano.

O objetivo é propor um conceito de resiliência da mobilidade urbana sob a perspectiva energética e sociológica. Além disso, contextualizar de forma histórica o uso dos combustíveis fósseis pelo setor de transportes no mundo. Traçar o histórico da relação entre fontes de energia e sistemas de transporte ajuda a compreender as origens do problema e a refletir sobre possíveis repetições de eventos na atualidade.

Com base no exposto, esta discussão se justifica por:

- Ausência do debate sobre resiliência da mobilidade urbana, em um contexto de dependência nos sistemas de transporte motorizados, a base de combustível fóssil;

- Número reduzido de trabalhos sobre a vulnerabilidade da mobilidade urbana;

- Interesse de contribuir com a comunidade acadêmica e comunidade em geral, numa área de relevância central para o desenvolvimento sustentável e estável das nossas cidades;

- Existência de poucos trabalhos na área dos transportes que explicitam as origens do uso dos combustíveis fósseis a partir de análises sociológicas e geográficas.

Buscando por termos "urban mobility resilience" e "resilience of urban mobility" em websites de banco de dados de trabalhos acadêmicos (em julho de 2014), como "google scholar", "Web of Science" e "Science Direct", não se encontrou trabalhos que definam um conceito de resiliência da mobilidade urbana. Entretanto, existe o conceito de resiliência urbana, que trata de perspectivas diversas, como por exemplo, ecológica, de riscos naturais e humanos, da economia regional e urbana e da perspectiva governamental e institucional (Agudelo-Vera et al., 2012; Alberti, et al., 2003; Collier, et al., 2013; Galderisi, 2014; Jabareen, 2013; Leichenko, 2011; Vale e Campanella, 2005).

Dentre as ênfases dos trabalhos que abordam a resiliência urbana, estão desastres naturais, redução de disponibilidade de recursos naturais, conflitos geopolíticos, etc. Não se encontrou nestes trabalhos abordagens relacionadas a mobilidade urbana e transportes. Desta forma, uma proposta de um conceito (incipiente) de resiliência da mobilidade urbana, com embasamento teórico, pode oferecer uma contribuição científica para futuros trabalhos.

Além disso, como já exposto anteriormente, existem poucos trabalhos que abordam a perspectiva energética e sociológica no transporte e na mobilidade (Vasconcellos, 2014). A diferença entre um trabalho sob a perspectiva social e sociológica, é que a primeira busca compreender os impactos dos aspectos do transporte sob as questões sociais, e a segunda localiza a sociedade como ator de mudanças dos aspectos da mobilidade e do transporte (Vasconcellos, 2014).

Com base na dificuldade de encontrar definições para o conceito de resiliência da mobilidade urbana, este trabalho utiliza referências como Vasconcellos (2014), Castells $(2009$; 1983) e Harvey (2008) para auxiliar na compreensão da lógica da construção do espaço urbano e, consequentemente, entender a lógica da mobilidade, e assim ter mais clareza na relação entre sociedade e mobilidade urbana.

Desta forma, este artigo está divido em quatro seções, além da introdução. Primeiramente, apresentase uma contextualização histórica do combustível fóssil no mundo e sua relação com o setor de transpor- 
tes. Em seguida, há um embasamento teórico utilizado para construir o conceito proposto neste artigo. Depois, o conceito de resiliência da mobilidade urbana é apresentado, cruzando o embasamento teórico da mobilidade urbana com o conceito de resiliência socioecológica. Por último, o trabalho é concluído com um esclarecimento sobre a contribuição desta proposta conceitual no âmbito dos estudos sobre mobilidade urbana.

\section{CONTEXTUALIZAÇÃO HISTÓRICA DO COMBUSTÍVEL FÓSSIL NO MUNDO E SUA RELAÇÃO COM O SETOR DE TRANSPORTE}

Desde os primórdios da história da humanidade, a energia é um elemento que possui um papel fundamental para o desenvolvimento, desde as sociedades coletoras, agrárias até as industrializadas (Heinberg, 2003; Schlör et al., 2012). Ao longo da história, diferentes fontes de energia foram agregadas, em diversos setores (Schlör et al., 2012).

Por sua utilidade e abundância, a madeira era a principal fonte de energia na idade média. Sua aplicação consistia em construir casas, armas, veículos de tração animal e utensílios (usados na agricultura e outros setores). Além disso, a madeira também era utilizada na preparação de alimentos, calefação e iluminação (Heinberg, 2003).

Neste período, o aumento da população e a exploração intensa da madeira gerou a escassez deste recurso, e consequentemente a necessidade de encontrar alternativas. De acordo com Schlör et al. (2012), o primeiro sistema sustentável surgiu em meados do século XVI, quando sistemas feudais alemães desenvolveram leis que protegiam florestas. Entretanto, foi a exploração intensa do carvão que evitou um colapso econômico e social nesta época (Heinberg, 2003; Schlör et al., 2012).

Embora o carvão já fosse uma fonte de energia conhecida na idade média e já utilizada para calefação e para cozinhar, apenas a redução da disponibilidade de madeira permitiu o aumento de sua exploração. O carvão era conhecido como "rocha negra" (black stone) e considerado como uma fonte de energia inferior, por conta da fumaça e poeira gerada (Nef, 1977).

Apesar da poeira e fumaça, o aumento do uso do carvão nos séculos seguintes estimulou avanços e descobertas no setor manufatureiro e metalúrgico (Gilbert e Perl, 2008; Nef, 1977). No final do século XVIII, a alta demanda de carvão encorajou o desenvolvimento de trilhos feitos de aço, que serviam para dar estabilidade a vagões tracionados por cavalos (Gilbert e Perl, 2008). Assim, permitindo a movimentação de maior quantidade de carga.

No início do século XIX, foi implementado na Inglaterra o primeiro trem movido a queima de carvão, por conta da superioridade de tração, em comparação com vagões tracionados por cavalos (Rodrigue et al., 2013). Em meados do século XIX, navios começaram a trocar energias renováveis (vento e força do homem) por energia a vapor (queima de carvão), assim aumentando a velocidade e capacidade de carregamento (Gilbert e Perl, 2008).

Durante o século XIX, quando as máquinas proliferaram, o óleo vegetal e de baleias eram utilizados para lubrificação e também utilizado em lâmpadas (Australian Government, 2013). Com a crescente demanda por óleo de baleia, esta espécie de valor comercial passou a ser caçada até o ponto de sua extinção (Martin, 2001). Com o início da extração e refinamento de petróleo no final do século XIX, o problema com a escassez de óleo de baleia foi resolvido. Além disso, no início do século XX, houve a descoberta e implementação do gás natural e eletricidade nas cidades, o que contribuiu com o setor industrial e a infraestrutura urbana (Heinberg, 2003).

O século XX é conhecido como a "era do petróleo", por conta do crescente uso deste recurso nos setores de transporte, agricultura, indústria e nas tecnologias utilizadas em guerras (Heinberg, 2003). No caso do setor de transportes, é possível afirmar que a indústria automobilística desempenhou um papel importante para o desenvolvimento dos Estados Unidos e outros países, entre 1920 e 1970 (Rodrigue et al., 2013; Gilbert e Perl, 2008; Hanson \& Giuliano, 2004). Ademais, em meados do século XX, o setor de transporte aéreo começou a movimentar pessoas e cargas pelo mundo (Rodrigue et al., 2013; Gilbert e Perl, 2008). 
De uma perspectiva histórica, observa-se que o século XX marca o início do crescente uso de petróleo, inicialmente com o objetivo de atender as necessidades da sociedade, em relação ao crescimento da produção industrial, otimização do transporte e a modernização da vida urbana. Além disso, as descobertas científicas, como automóveis, pesticidas e tipos de refino de petróleo desempenharam papéis importantes em todos os setores da sociedade, e foram implementadas tanto em áreas rurais quanto urbanas ao longo do tempo.

Após a segunda guerra mundial, o consumo de petróleo cresceu em escala global, principalmente nos Estados Unidos e países europeus. Entretanto, pela segunda metade do século XX, os Estados Unidos não estavam extraindo petróleo suficiente para atender a demanda do país (Hopkins, 2008). Desta forma, passaram a depender do mercado externo de petróleo, principalmente da Arábia Saudita, Iraque, Iran, Kuwait e Emirados Árabes (primeiros países a compor a OPEC), sendo maior parte do petróleo vindo dos primeiros três (Newman et al., 2009; Hopkins, 2008).

De uma perspectiva geopolítica, o suporte dos Estados Unidos a Israel teve severas consequências em 1973, quando a coalisão dos Estados Árabes, liderados pelo Egito e Síria passaram a "linha de cessar fogo", para invadir a Península do Sinai e Colinas de Golan, iniciando a guerra de Yom Kippur (Sagan, 1979). Enquanto os Estados Unidos apoiavam Israel, a União Soviética dava suporte aos Estados Árabes, criando um confronto entre as duas potencias neste período. Este confronto influenciou no embargo de petróleo dos Estados Árabes contra os Estados Unidos.

Este embargo gerou filas "intermináveis" nos postos de gasolina e, além disso, o preço do barril de petróleo subiu de 3 para 12 dólares (Hopkins, 2008; Heinberg, 2003; Goldemberg et al., 1987). Em 1979, um novo período de guerra começou no Oriente Médio, entre Iraque e Iran, e novamente a redução da disponibilidade de petróleo afetou o preço, aumentando de 12 para 30 dólares por barril (Heinberg, 2003; Goldemberg et al., 1987). O aumento do preço do petróleo afetou a economia global, além disso, a subsequente inflação gerou um aumento de preço dos bens de consumo, criando um "efeito dominó" e afetando o dia-a-dia de cidadãos em todo o mundo (Heinberg, 2003). Crises subsequentes foram evitadas nas duas últimas décadas do século XX, por conta da descoberta de reservas de petróleo no Mar do Norte, na costa da Nigéria, Angola, México e no Alasca.
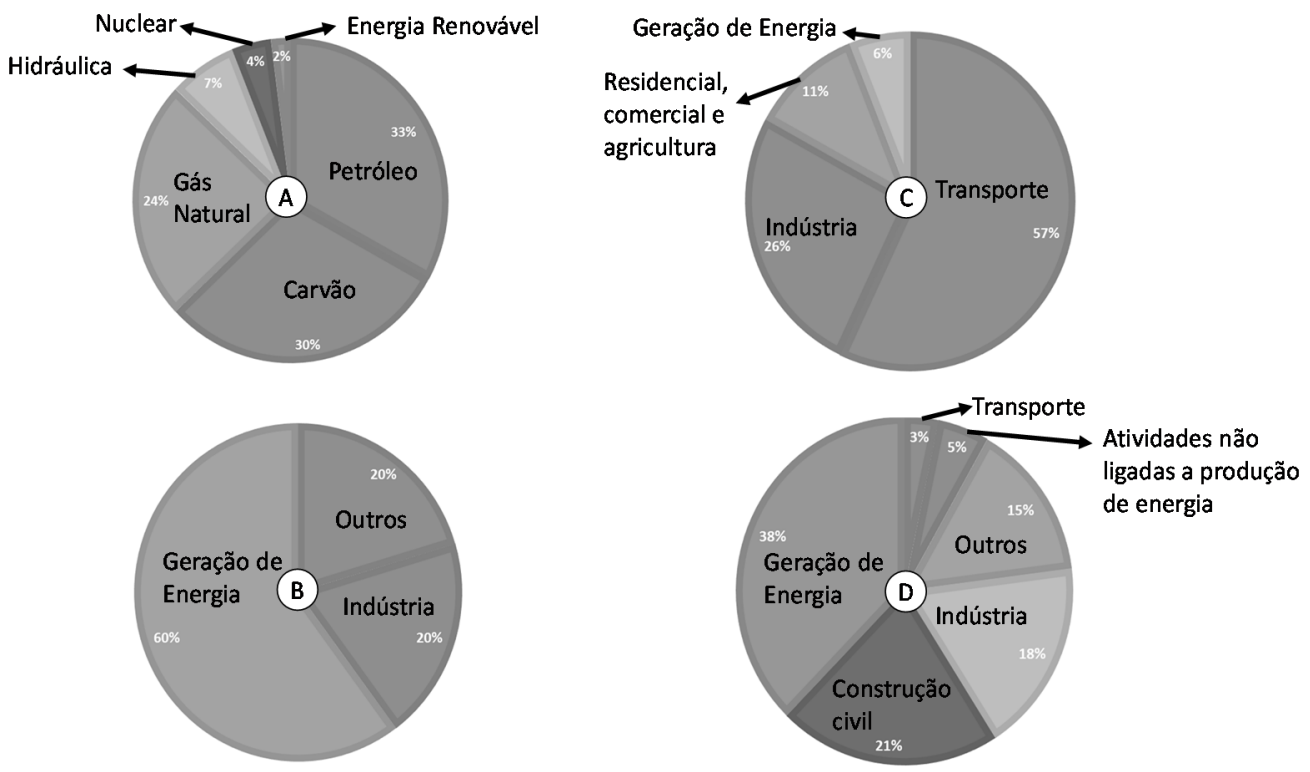

(a) Matriz do consumo global de energia primária em 2012 (BP, 2013)

(b) Matriz do consumo de carvão por setor em 2011 (IEEJ, 2013)

(c) Matriz do consumo de petróleo por setor em 2010 (OPEC, 2013)

(d) Matriz do consumo de gás por setor em 2011 (IEEJ, 2013)

Figura 1: Matriz de consumo de energia primária e energia por setor no mundo 
Crises como de 1973 e 1979 aconteceram novamente em 1990 e 2008. Em 1990 a crise foi deflagrada pela invasão do Iraque ao Kuwait, e 2008 por razões que ainda estão em discussão (Hamilton, 2009). Hamilton (2009) argumenta que a causa provável para a crise de 2008 é a falha de produção, que não acompanhou o crescimento da demanda por petróleo. Além disso, é importante ressaltar que na crise de 2008 o preço do barril de petróleo aumentou de 50 para 140 dólares (IEA, 2015b) e que o PIB global apresentou queda logo após as crises de 1990 e 2008 (World Bank, 2015).

Ainda que este trabalho não explore a fundo questões relativas a guerras, é interessante ressaltar que o início do século XXI é marcado por vastas discussões em relação ao ataque de 11 de setembro (2001), nos Estados Unidos. Neste caso, houve discussões sobre os interesses dos Estados Unidos no Oriente Médio, se as invasões eram para combater o terrorismo ou para ter acesso às reservas de petróleo (Moore, 2004).

Todos estes eventos evidenciaram a crescente significância que o petróleo passou a ter com o aumento de sua demanda. Qualquer variação no preço do barril de petróleo pode afetar a economia global, e consequentemente o setor de agricultura e industrial, levando ao aumento de preço de alimentos e bens de consumo, impactando também o setor de transportes. Cabe lembrar que muitas metrópoles hoje são altamente dependentes dos meios de transporte motorizados, movidos a gasolina e diesel.

Com relação a dados recentes neste tema, a Figura 1 apresenta dados da matriz global de consumo de energia primária e o percentual de consumo de cada fonte de energia por setor no mundo.

Analisando de forma mais abrangente, observa-se que os combustíveis fósseis ocupam maior parte da figura A (figura 1), que representa a matriz global de consumo de energia primária, compondo um valor de $87 \%$ de todas as fontes de energia primária. Em ordem decrescente de consumo, está o petróleo (33\%), carvão (30\%) e gás natural (24\%). É importante frisar que para o Banco Mundial, em 2011, os combustíveis fósseis compunham $81 \%$ do consumo de energia primária no mundo, ou seja, houve um aumento de $6 \%$ no consumo global de combustíveis fósseis. Entretanto, este aumento pode ser questionável, por serem dados calculados por instituições distintas.

Com maior atenção em cada um dos combustíveis fósseis, é possível observar o quanto cada setor é dependente de cada tipo de fonte de energia. A figura B (figura 1) mostra a matriz de consumo de carvão por setor no mundo. No caso do carvão, o setor de geração de energia compõe $60 \%$ de todo o consumo, em seguida vem a indústria (20\%) e outros setores (20\%). De acordo com o Instituto de Economia Energética do Japão (IEEJ), até 2040 o percentual de consumo de carvão pelo setor de geração de energia pode chegar a $70 \%$.

No caso do petróleo (C na figura 1), em 2010, a maior parte é consumida pelo setor de transportes (57\%), em seguida a indústria (26\%), depois vem o setor residencial, comercial e agrícola (11\%), e por último o setor de geração de energia (6\%). De acordo com a OPEC (2013), até 2035 o transporte pode aumentar para $60 \%$ no consumo total de petróleo.

No caso do gás natural (D na figura 1), em 2011, 38\% do consumo é pelo setor de geração de energia, $21 \%$ pela construção civil, $18 \%$ pela indústria, $3 \%$ pelo transporte, $5 \%$ por atividades que não estão ligadas à produção de energia, e 15\% por outras atividades. É previsto que, até 2040 , o setor de geração de energia vai compor $40 \%$ do consumo total de gás natural (IEEJ, 2013).

Os setores mais dependentes de combustíveis fósseis são transporte, geração de energia e indústria (BP, 2014). Apesar de, em termos de energia, o transporte ser o que menos consome dentre estes três (BP, 2014), o transporte é o setor que menos utiliza energia renovável dentre os três (IEA, 2015a). Além disso, as previsões mostram uma tendência de crescimento do consumo do combustível fóssil para os próximos anos (BP, 2014), sendo que o petróleo é um recurso natural limitado. Os cálculos de um futuro pico de petróleo em termos de produção global podem ainda ser incertos, mas em termos locais já aconteceram, e consequentemente afetaram economias e sociedade nestes locais. Entre os países que já alcançaram o pico de petróleo estão (Association for the Study of Peak Oil USA, 2015): os Estado Unidos, em 1970; Indonésia, 1994; Venezuela, em 1997; Reino Unido, em 1999; Noruega, em 2001; dentre outros. 
Nesta revisão histórica da relação do transporte e fontes de energias, observou-se diferentes razões pelo qual o homem sente a necessidade de buscar novas fontes de energia. A contradição, hoje, é que, apesar dos motivos "nobres", no que diz respeito ao meio ambiente e sociedade, percebe-se que as tendências, em termos globais, são contrárias aos interesses. 0 consumo de combustíveis fósseis aumenta, ademais, a sociedade e o meio ambiente ainda estão sofrendo com o excesso de uso destes recursos naturais não renováveis. Este fato deixa em aberto a real efetividade das soluções sustentáveis. 0 conceito de resiliência da mobilidade urbana vem para acrescentar, pois busca entender a mobilidade urbana no sentido da funcionalidade e continuidade frente a ameaças externas e espontâneas.

\section{BASES TEÓRICAS: SUPORTE PARA A PROPOSTA DO CONCEITO DE RESILIÊNCIA DA MOBILIDADE URBANA}

Este tópico apresenta as bases teóricas utilizadas para construir o conceito de resiliência da mobilidade urbana. Primeiramente, trata do entendimento da mobilidade urbana sob a perspectiva sociológica, para depois propor o conceito. Este conceito também agrega outros conceitos, como segurança energética (Winzer, 2012), resiliência (Folke et al., 2010), e segurança humana (Nações Unidas, 2009).

Observou-se que a perspectiva sociológica está ligada ao papel da sociedade na construção do significado urbano (Castells, 2009; 1983), e consequentemente nas condições necessárias para o desenvolvimento social. Este contexto motiva agregar neste trabalho o conceito de segurança humana, em que trata destas condições de desenvolvimento social.

\subsection{Mobilidade Urbana e a Cidade: Perspectiva Sociológica}

O sistema de transporte garante o funcionamento da cidade, facilitando os cidadãos a realizarem suas atividades diárias (Wachs, 2004). É importante destacar que o propósito do sistema de transporte envolve atender a demanda da mobilidade, superando obstáculos, como distancia, tempo, divisões administrativas e topografia (Rodrigue et al., 2013). Mas, além de seu propósito, para haver a existência de um sistema de transporte é necessário que dois requisitos sejam atendidos. Primeiro a necessidade de atender a uma demanda de mobilidade, como apontado anteriormente. Segundo, haver a disponibilidade de recursos energéticos adequados para os sistemas de transporte utilizados. Pode-se também chamar estes requisitos, respectivamente, de demanda direta e indireta (Rodrigue et al., 2013). Desta forma, é entendido que estes são os requisitos iniciais para implementação de um sistema de transporte.

Mais especificamente, um sistema de transporte é complexo e possui uma interdependência de fatores que podem afetar o sistema ou serem afetados por ele (Hoyle e Knowles, 1998). O sistema de transporte como um sistema interativo pode ser dividido em três etapas: demanda; implementação; avaliação. As etapas estão relacionadas entre si, assim como os fatores. A seguir explicita-se alguns destes fatores, de cada etapa deste sistema interativo:

- Demanda - Esta etapa envolve a compreensão das condições demográficas (ex. estrutura social; densidade e distribuição populacional; e nível da demanda) e estrutura econômica (ex. recursos disponíveis; uso do solo; distribuição de empregos);

- Implementação - Esta etapa consiste na tomada de decisão, com base na estrutura política (ex. planejamento; e leis/regulamentações), preocupações ambientais (ex. impactos ambientais; e preservação do ecossistema), finanças (ex. receita; alocação de recursos; nível de investimento) e tecnologias disponíveis (ex. relevância; e custo);

- Avaliação - Nesta etapa considera-se as características de uso (ex. custo; e comportamento), escala (ex. local, nacional ou global), dimensões (ex. espacial; temporal; e estrutural) e influencias (ex. meio ambiente; uso do solo; e desenvolvimento social e econômicos).

Além da relação entre estas etapas e fatores que envolvem o planejamento e implementação de um sistema de transporte. Destaca-se também, que existe um fator histórico que torna o sistema dinâmico, e que induz um sistema cíclico, de forma que etapas anteriores estão sempre sendo reavaliadas, com a 
intenção de estar adequando o sistema à novas condições de existência (Hoyle e Knowles, 1998).

Destaca-se também como outra perspectiva dos estudos de mobilidade urbana a relação do sistema de transporte e o espaço urbano. Com relação a isto, observa-se que existe uma relação recíproca, ou seja, a estrutura espacial pode ser um fator determinante para o sistema de transporte e vice-versa (Rodrigue et al., 2013).

Existem dois tipos de reciprocidade que explicam esta relação do transporte e espaço urbano (Rodrigue et al., 2013). Primeiramente a reciprocidade da mobilidade, que consiste na relação de dependência que as atividades do espaço urbano têm com o sistema de transporte. Com base na influência que $o$ transporte tem sobre as atividades econômicas, determinadas localidades da cidade podem ter maior ou menor acessibilidade a terminais de transporte, como estações de ônibus, metro e/ou trem.

Em seguida, há a reciprocidade da localidade, que envolve a distribuição dos diferentes usos de solo na cidade e as características do sistema de transporte. Ou seja, entende-se que um centro de negócios (Central Business District) tende a direcionar as redes viárias e sistemas de transporte para esta área, pela concentração de empregos e atividade comerciais.

Ainda abordando a relação do transporte e espaço urbano, não há uma forma fixa de ver esta relação, até porque cada caso possui suas particularidades e históricos de desenvolvimento social e urbano. Wegener (2004), por exemplo, identificou mais de 20 modelos contemporâneos que buscam explicar esta relação. E através da revisão de cada um destes modelos, Wegener (2004) foi capaz de destacar fatores que não são levados em consideração, como impactos ambientais (que não estão somente relacionados a poluição atmosférica) e desigualdade sócioespacial.

É observado, atualmente, modelos de planejamento de transportes contemporâneos que buscam atender diretrizes sustentáveis (Rodrigue et al., 2013), com o objetivo de trazer equidade social, reduzir impactos ambientais e melhorar a qualidade de vida nas cidades. Estas diretrizes vêm complementar o modelo tradicional de quatro etapas, adicionando no processo, avaliações de impactos ambientais, socioeconômicos e espaciais.

Entretanto, Vasconcellos (2014) afirma que existem poucos estudos na área de transportes que apresentam uma perspectiva sociológica. Este autor explica que é mais comum encontrar trabalhos com características mais descritivas, que consistem em avaliar os impactos sociais. Enquanto, uma perspectiva sociológica tem um papel de relacionar padrões de mobilidade com as deficiências sociais, políticas, econômicas e institucionais.

Desta forma, antes de propor uma sistematização e conceituação da resiliência da mobilidade urbana, este artigo apresenta uma visão teórica da mobilidade urbana, construída através de uma revisão de literatura, com ênfase na perspectiva sociológica. Ou seja, estabelecendo a mobilidade urbana como objeto central de estudo, ao invés do sistema de transporte em si.

A figura 2 é um diagrama que representa o framework da mobilidade urbana, ou seja, representa a relação da mobilidade urbana de um indivíduo ou grupo social e os elementos que exercem influência na mobilidade. Sob a lógica da demanda direta e indireta do Rodrigue et al. (2013), quando se explicita o contexto espacial que cria a necessidade da implantação de um sistema de transporte, entende-se que algo similar se passa com a mobilidade urbana. Ou seja, neste artigo entende-se que o ato da movimentação pode ser estimulado ou obstruído por elementos em âmbito sociológico (influência direta) e externos (influencia indireta). Estes elementos externos podem ser interpretados como o ambiente construído, políticas públicas, condições geográficas, dentre outros. A figura 2 é a forma escolhida para demonstrar a relação destes elementos.

A proposta de compreensão lógica da mobilidade urbana, parte do entendimento do espaço urbano como uma unidade ecológica, com base na Escola de Chicago, entretanto com os elementos sociais como questões centrais do sistema (Castells, 2009). Ademais, parte-se da ideia de que o espaço urbano é um produto de interesses e contradições sociais, que estão espacialmente distribuídos na cidade (Castells, 2009). De forma geral, este processo de produção do 
espaço urbano pode ser geograficamente identificado por três elementos: Ideologia das classes sociais; economia; e político-institucional (Castells, 2009).

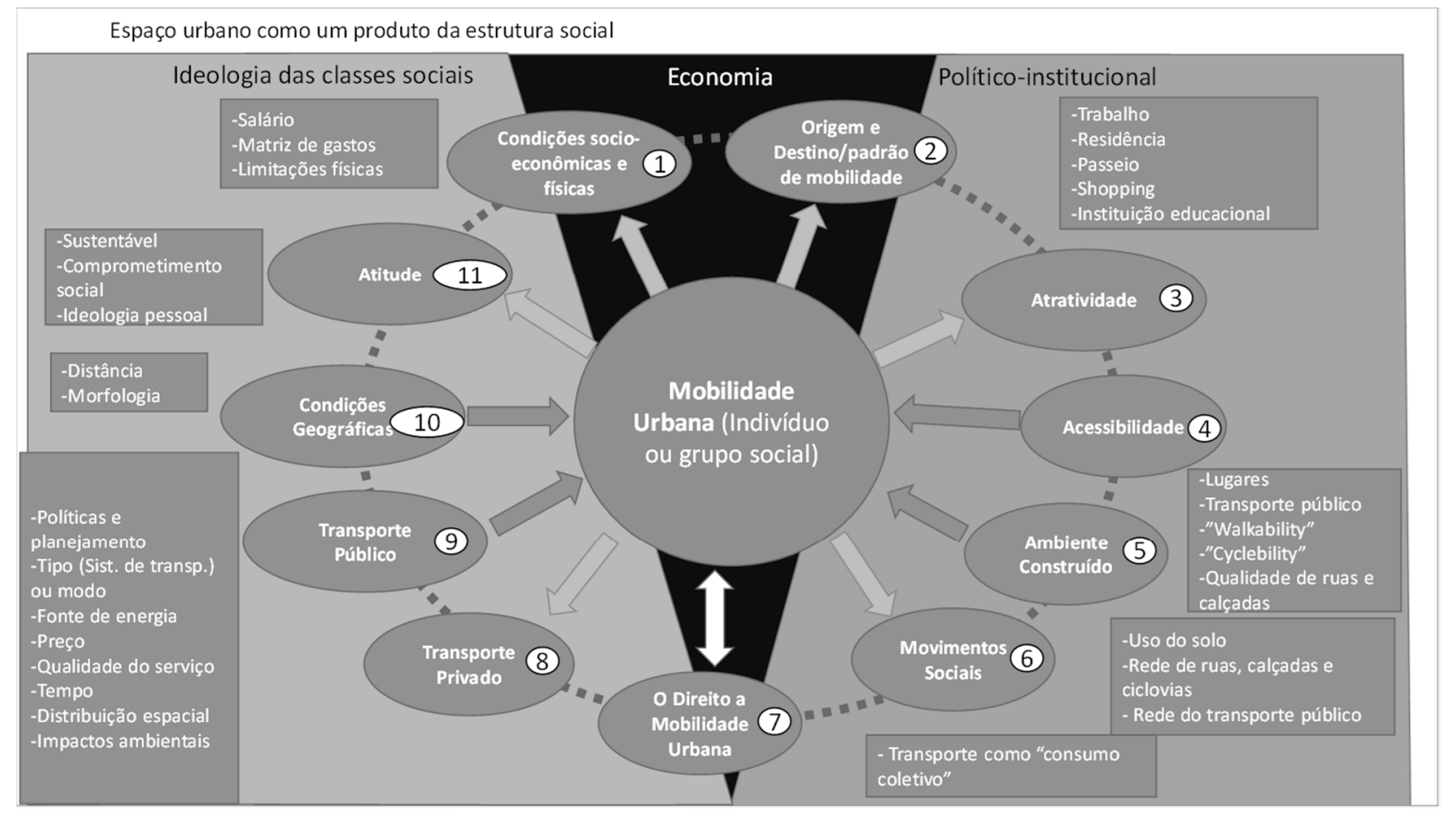

Figura 2: Representação dos elementos que exercem influência sob a mobilidade urbana

A ideologia de classes está relacionada com os interesses de cada classe social, que estão representados, desde a localização de moradia, até as modificações urbanas feitas por um grupo ou indivíduos. Ou seja, este elemento pode estar sendo representado de diversas formas no espaço, levando em consideração que decisões de grupos sociais ou indivíduos podem ser concretizados no espaço gerando, por exemplo, o processo de auto-segregação.

O elemento economia está relacionada com a distribuição espacial das atividades econômicas da cidade, considerando comercial, industrial e serviços. 0 elemento político-institucional se refere à distribuição e configuração espacial dos bairros e distribuição espacial das repartições públicas, por exemplo, prefeitura, setores da prefeitura (ex. transporte, planejamento urbano, etc.), dentre outros.

Como o objetivo é enfatizar a perspectiva sociológica, este trabalho propõe o conceito de resiliência da mobilidade urbana com base nos elementos que representam as influências diretas na mobilidade urbana. Na figura 2, observa-se que estes elementos são (tabela 1): (1) condições socioeconômicas e físicas; (2) origem e destino; (3) atratividade; (6) movimentos sociais; (7) o direito a mobilidade urbana; (8) transporte privado; e (11) atitude.

Os elementos de influência indireta estão relacionados ao ambiente construído, a oferta de serviços e oportunidades de mobilidade que não foram, necessariamente, planejados e implementados por aqueles que se movimentam na cidade e "consomem" este espaço (Rodrigue, Comtois, \& Slack, 2013; Hanson \& Giuliano, 2004). Além disso, existem as condições naturais do espaço que estão relacionadas, por exemplo, à morfologia do terreno (Rodrigue, Comtois, \& Slack, 2013; Hanson \& Giuliano, 2004).

A proposta teórica de estabelecer a mobilidade urbana como centro do sistema é uma alternativa para estudos de transporte, em tempos que perspectivas de sustentabilidade e resiliência são crescentes e atentam em reduzir distancias, custos, impactos ambientais, estimular mudanças de comportamento e trazer maior equidade no acesso aos meios de transporte e as atividades da cidade.

Esta seção dá uma visão geral da mobilidade urbana, com base em elementos que podem influenciar a mobilidade dos indivíduos e grupos sociais dentro de uma área urbana. 0 framework contribui com uma 
perspectiva sociológica sobre mobilidade urbana, através de uma compreensão da produção do espaço urbano e o papel da sociedade neste processo.

Tabela 1: Elementos de influência direta na mobilidade urbana

\begin{tabular}{|c|c|c|c|}
\hline Fig. 2 & $\begin{array}{l}\text { Tipo de } \\
\text { influência }\end{array}$ & Descrição & Referência \\
\hline 1 & Direta & $\begin{array}{l}\text { Este diz respeito a informações como classe, etnia, religião, sexo, idade e divi- } \\
\text { são social e técnica do trabalho. Existem subconjuntos de informações que po- } \\
\text { dem estar dentro destes fatores. }\end{array}$ & (Vasconcellos, 2014) \\
\hline 2 & Direta & $\begin{array}{l}\text { A matriz de viagem de um grupo ou indivíduo, ou seja, a informação do destino } \\
\text { e origem das viagens. }\end{array}$ & (Vasconcellos, 2014) \\
\hline 3 & Direta & $\begin{array}{l}\text { Este está relacionado com a razão pela qual um indivíduo ou grupo está exer- } \\
\text { cendo a viagem, além disso, onde uma pessoa é capaz de atender as necessi- } \\
\text { dades no espaço urbano. }\end{array}$ & (Vasconcellos, 2014) \\
\hline 6 & Direta & $\begin{array}{l}\text { Este está relacionado aos movimentos sociais, em específico, que têm como } \\
\text { objetivo o "consumo coletivo", ou seja, aprimorar o serviço de uma atividade } \\
\text { que todos teriam que ter acesso. }\end{array}$ & (Castells, 1983) \\
\hline 7 & $\begin{array}{l}\text { Direta/ In- } \\
\text { direta }\end{array}$ & $\begin{array}{l}\text { Este diz respeito ao direito de participar no processo de planejamento e ela- } \\
\text { boração de políticas e de se beneficiar das opções de mobilidade (direta ou } \\
\text { indiretamente). }\end{array}$ & (Harvey, 2008) \\
\hline 8 & Direta & $\begin{array}{l}\text { Este diz respeito à posse de transporte privado e frequência de uso. Este ele- } \\
\text { mento também sugere outros fatores subjetivos relacionados com a razão pela } \\
\text { qual um prefere transporte privado ao invés do público. }\end{array}$ & (Vasconcellos, 2014) \\
\hline 11 & Direta & $\begin{array}{l}\text { Entendendo que existe a ideologia de uma classe social, este elemento está } \\
\text { relacionado com a ideologia de um indivíduo ou um grupo, em relação espe- } \\
\text { cificamente à atitude, e como este aspecto pode influenciar na vontade de se } \\
\text { adaptar. Por exemplo, o compromisso sustentável ou social, ou outra ideologia } \\
\text { pessoal. }\end{array}$ & (Castells, 2009) \\
\hline
\end{tabular}

\section{RESILIÊNCIA DA MOBILIDADE URBANA: PROPOSTA CONCEITUAL E DE SISTEMATIZAÇÃO}

Esta seção foca em propor um quadro conceitual da resiliência da mobilidade urbana (figura 3). Esta estrutura é construída sob a lógica sociológica, vendo o espaço como um produto das contradições sociais. Além da perspectiva teórica da mobilidade urbana apresentada anteriormente (seção 3), a lógica do conceito proposto aqui também agrega os seguintes conceitos: resiliência; segurança energética; e segurança humana.

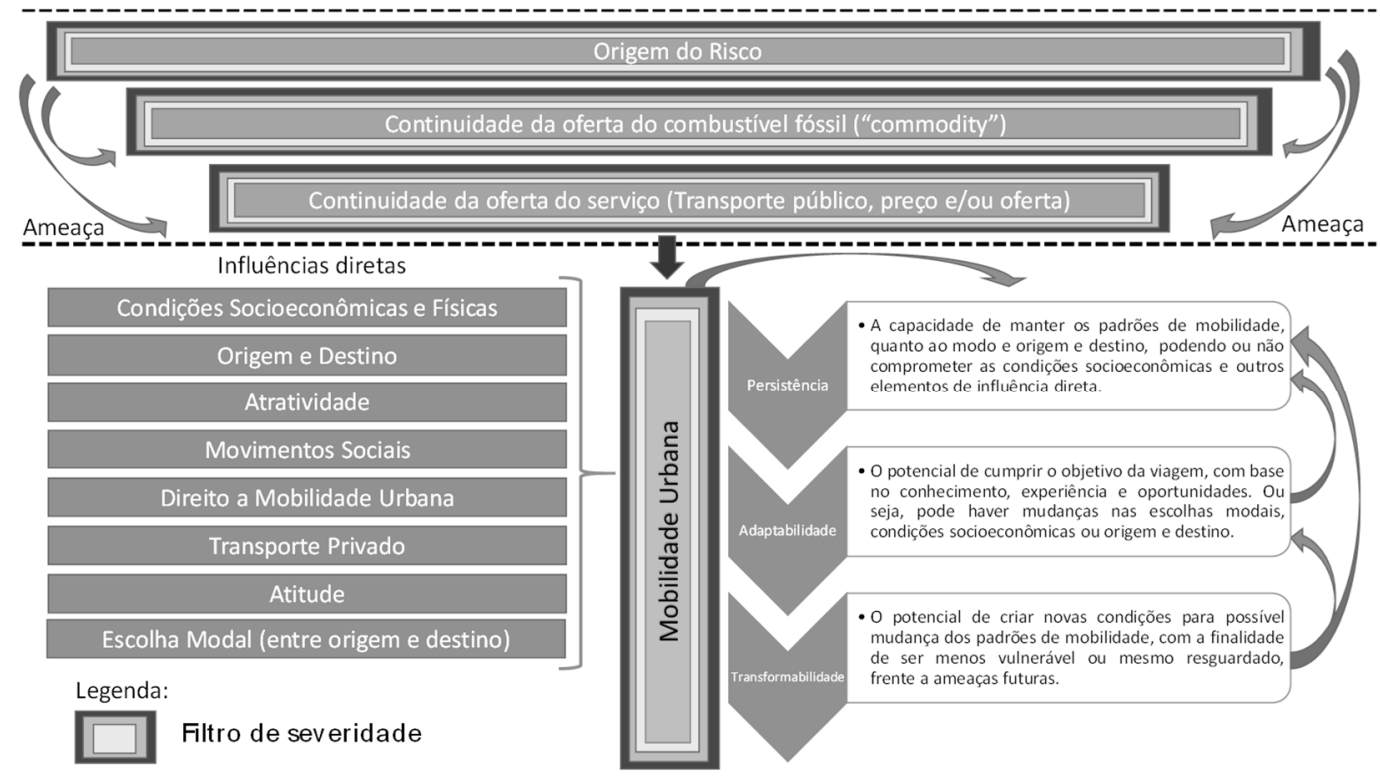

Figura 3: Framework da resiliência da mobilidade urbana 
Inicialmente é possível observar na figura 3 o setor da ameaça à mobilidade urbana. Esta ameaça é baseada no conceito de segurança energética de Winzer (2012). Para Winzer (2012) a segurança energética é um conceito amplo, pois são inúmeros os riscos que podem afetar a cadeia de produção até o consumo em diferentes âmbitos. Ou seja, não existe uma ordem determinada para quando a cadeia de fornecimento energético é afetada, pois as causas são diversas.

Em seu trabalho, Winzer (2012) buscou unir de forma mais científica possível as questões ligadas à segurança energética. Primeiramente, o autor explicita que há diferentes tipos de origens do risco, que podem ser técnicos (ex. falha mecânica, emissões indesejadas, falha termal, etc.), humano (ex. risco de demanda, terrorismo, instabilidade política, etc.) ou natural (ex. esgotamento de recurso natural, desastre natural, etc.). Dependendo da origem do problema, existem três setores que podem ser afetados: a continuidade do fornecimento de commodities; a continuidade do fornecimento do serviço de transporte público; ou (a continuidade do) preço acessível do combustível.

Desta forma, é possível perceber que, apesar do transporte público não ser considerado influência direta, este elemento não deixa de estar incluído no quadro teórico da resiliência da mobilidade urbana. Isto quer dizer que, o papel do transporte público é significante para a resiliência da mobilidade urbana, pois dependendo de sua configuração e características, este serviço pode estar mais ou menos vulnerável a possíveis riscos, sejam eles técnicos, humanos ou naturais. Consequentemente afetando menos ou mais a mobilidade urbana.

Neste quadro conceitual, a partir do momento que a mobilidade urbana sofre uma ameaça, as influências diretas passam a apresentar um papel significante, pois dependendo das características socioeconômicas, origem e destino (distância), atratividade, e dos outros elementos, o grupo social ou indivíduo terá mais ou menos possibilidades de se adaptar, frente às adversidades (ameaças), que pode ser o aumento do preço do petróleo ou redução de sua disponibilidade.

É compreendido que a resiliência é um conceito que pode ser segmentado em três etapas (Folke, et al., 2010): persistência; adaptabilidade; e transformabilidade. A primeira etapa está relacionada com o potencial de um indivíduo ou grupo manter seus padrões de mobilidade, afetando talvez as condições socioeconômicas, sem comprometer a qualidade de vida. A adaptabilidade está relacionada com o potencial de adotar alternativas diferentes aos padrões usuais de mobilidade, também sem comprometer a qualidade de vida. E a transformabilidade está ligada com o potencial de criar novas condições de adaptabilidade e persistência, frente a futuras ameaças.

0 próximo elemento que pode ser observado na figura 3 é o filtro de severidade. Este elemento representa o nível de resiliência em relação a cada aspecto ligado às influências diretas. Esta seção propõe utilizar o conceito de segurança humana para estabelecer os filtros de severidade das condições socioeconômicas e sua relação com os outros elementos de influência direta.

Utilizando a matriz de gastos de um indivíduo ou grupo social, o conceito de segurança humana das Nações Unidas (2009) serviria de base para determinar o menor nível de resiliência. A partir do momento que uma ameaça do setor de combustível fóssil afetar as condições básicas da segurança humana, a resiliência estaria em nível baixo, estas condições estão relacionadas a assegurar: economia da família; moradia; higiene pessoal e saúde; educação; vestuário; e alimentação. 0 nível médio de resiliência seria marcado pelo corte de gastos em atividades de lazer, e o alto nível de resiliência, seria marcado apenas por afetar parte do rendimento que é economizado.

Desta forma, partindo da perspectiva da segurança humana, esclarecida anteriormente, é possível estabelecer os filtros de severidade dos outros elementos de influência direta, entendendo que existem interações dinâmicas entre diferentes escalas e fatores da mobilidade urbana. Ou seja, o nível de resiliência gerado, partindo das questões socioeconômicas estão interligadas com o filtro de severidade dos outros fatores. A tabela 1, na seção anterior, descreve o significado de cada um dos elementos de influência direta. E com base nestas descrições, pode-se gerar formas de mensurar estes elementos quantitativa e qualitativamente.

A figura 4 apresenta a proposta de organização dos elementos de influência direta em um sistema de 
resiliência da mobilidade urbana, divido nas três etapas da resiliência sócio-ecológica, persistência, adaptabilidade e transformabilidade. Este sistema serve de base para a geração de um processo de análise da resiliência da mobilidade urbana.

Uma descrição mais detalhada deste sistema (figura 4) permite compreender o papel de cada um dos elementos na avaliação da resiliência da mobilidade urbana, e o como os filtros de severidade destes elementos influenciam na reação da mobilidade urbana frente a ameaças, como aumento de preço dos combustíveis fósseis ou falta da disponibilidade destes recursos. Este sistema pode ser lido da seguinte forma:

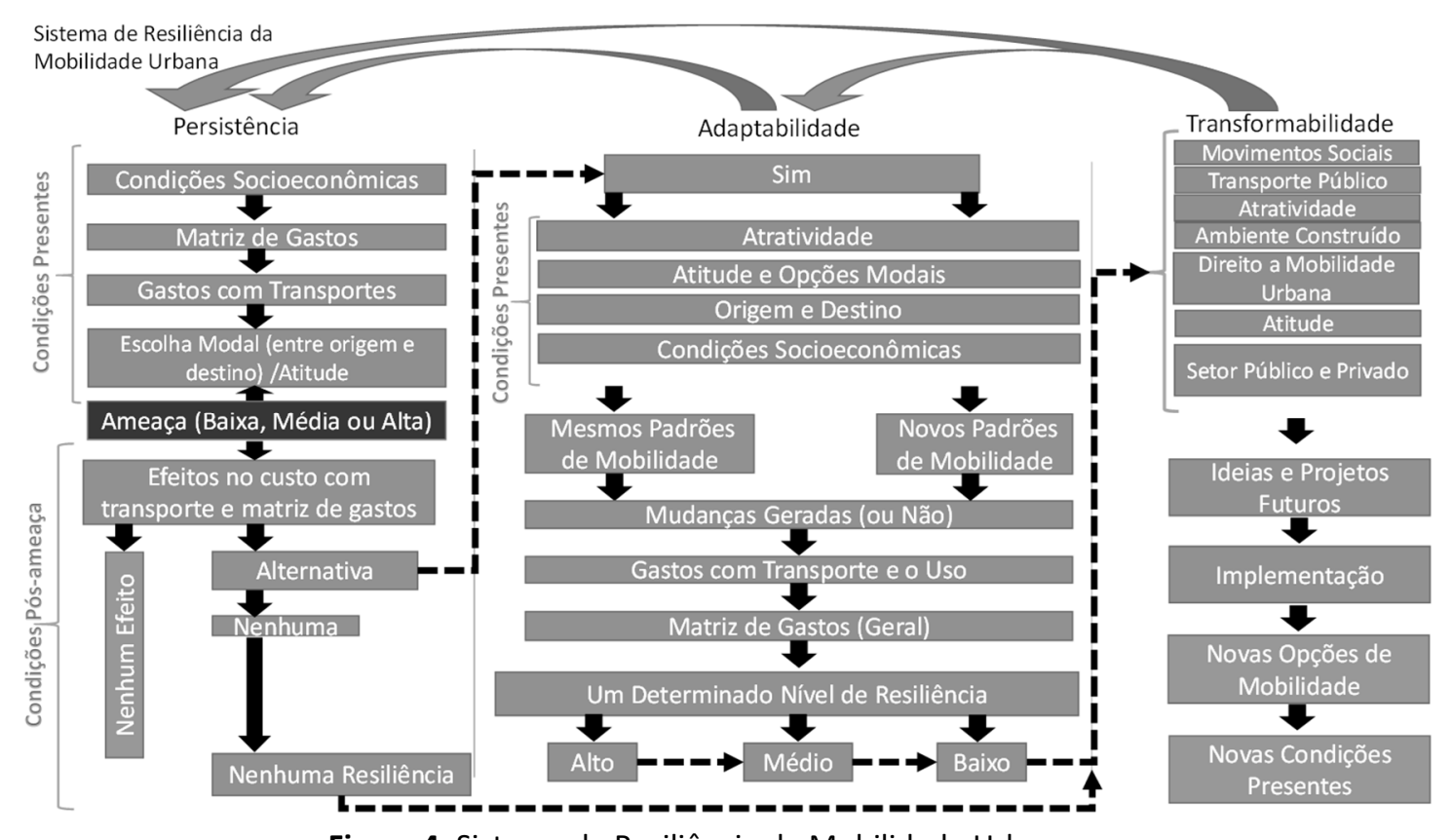

Figura 4: Sistema de Resiliência da Mobilidade Urbana

- Etapa da Persistências - Para começar, existe uma condição socioeconômica atual (presente matriz de gastos e nível salarial) e também um padrão de mobilidade, que é escolhido por causa de uma determinada atitude (lido também como motivação).

Quando estas condições presentes são confrontadas com uma ameaça - em especifico, aumento do preço da gasolina/diesel/gás natural ou dos transportes públicos a base de combustíveis fósseis - o grupo social e indivíduo em suas condições presentes, pode se resguardar de um efeito socioeconômico, por não utilizar nenhum modal que envolva este recurso energético. Entretanto, este não sendo o caso, deve-se avaliar as alternativas, já envolvendo a etapa da adaptabilidade.

- Etapa da Adaptabilidade - Envolve a capacidade de um indivíduo ou grupo social de se adaptar, frente a dificuldade de persistir quando ameaçado, com base na atratividade; atitude e opções modais; origem e destino; e condições socioeconômicas.

Atratividade: Nível de atração (lido também como interesse) de um indivíduo ou grupo social para determinadas localidades. Esta atratividade pode estar relacionada a oferta de empregos e serviços em localidades accessíveis por transportes não motorizados;

1. Atitude e Opções Modais: Aspecto comportamental, lidando com os motivos pelo qual certas escolhas são feitas - ou não, com base nas oportunidades de mobilidade (opções modais).

2. Estas escolhas podem envolver escolha modal, local de residência, local de trabalho, e inclusive ideologias pessoais (comprometimento com a sustentabilidade ou outras ideologias pessoais). 
3. Origem e Destino: A capacidade de realizar as mesmas atividades, considerando a troca da origem e/ou o destino, como por exemplo, mudar o local de residência e/ou de trabalho.

4. Condições Socioeconômicas: A capacidade de aprimorar o salário ou de gerenciar a matriz de gastos, sem afetar a qualidade de vida ou condições básicas de dignidade humana.

É importante considerar, que dificilmente as escolhas envolvendo cada um destes elementos podem ser feitos separadamente. Ou seja, são elementos e escolhas que estão interligados. E, além disso, as condições socioeconômicas estão intimamente ligadas as condições geográficas e ao comportamento de um indivíduo ou grupo social.

Os filtros de severidade dos elementos da adaptabilidade são estabelecidos, por exemplo, através dos níveis de acessibilidade a empregos próximo aos locais de residência; resistência ao uso de trem ou metrô, por motivos de segurança ou desconforto; a flexibilidade de mudar o local de residência ou trabalho, com base no custo da moradia e salários recebidos; a possibilidade de ter uma valorização salarial ou de gerenciar as finanças pessoais e familiares.

Ademais, cada localidade de uma cidade com suas particularidades geográficas e socioeconômicas, possui diferentes combinações de problemas e níveis de severidade, gerando diferente níveis de resiliência da mobilidade urbana. Com os problemas de adaptabilidade identificados, a próxima etapa é avaliar a transformabilidade.

- Etapa da Transformabilidade - Tem a intenção de avaliar de diferentes perspectivas as pressões e projetos para melhoria da mobilidade urbana. Esta etapa envolve analisar o papel dos movimentos sociais no processo de estimular o desenvolvimento de projetos de mobilidade não motorizados e independentes de combustíveis fósseis. Além disso, avaliar projetos de reestruturação urbana, se existe a intenção de descentralizar os postos de trabalho, com a intenção de reduzir as distancias das viagens a trabalho.

Outros elementos, que podem ser avaliados também, são o nível de inclusão dos cidadãos no processo de planejamento de transportes (direito a mobilidade urbana) e os esforços para mudar a atitude do cidadão com relação a mobilidade urbana, ou seja, a eficácia do "marketing positivo" no estímulo ao uso do transporte público, em específicos os meios não-motorizados.

Para finalizar esta seção, é possível observar que cada um dos elementos de influência direta pode compor diferentes etapas da resiliência (persistência, adaptabilidade ou transformabilidade). Neste sentido, quando um modelo empírico for construído, deve-se relacionar o significado de cada elemento e sua função dentro de cada uma das etapas da resiliência da mobilidade urbana.

\section{CONCLUSÕES}

Entende-se que quando lidando com a compreensão de perspectivas teóricas e construção de conceitos, que o trabalho é extenso e detalhado, entretanto é necessário a síntese do conteúdo para ter visibilidade acadêmica, em uma revista científica.

Este trabalho contribui de duas formas, primeiro com a contextualização histórica dos combustíveis fósseis e o setor de transportes. Em seguida, contribui com uma proposta conceitual e sistematização da resiliência da mobilidade urbana.

Este artigo explicitou os diferentes efeitos que os elementos de influência direta exercem sobre a o nível de resiliência mobilidade urbana. Além disso, argumentando a importância de utilizar as condições socioeconômicas como epicentro do modelo. Pois os custos com o transporte e seus efeitos sobre as condições econômicas de um indivíduo ou grupo social está intimamente relacionado com as formas de uso do espaço urbano.

O quadro conceitual desenvolvido aqui, pode servir de base para futuros trabalhos empíricos que queiram explorar o tema da resiliência da mobilidade urbana frente a dependência a combustíveis fósseis. Além disso, o modelo apresentado pode trazer insights que vão além do sistema de transporte em si, mas também considerando características urbanas e sociológicas. 


\section{AGRADECIMENTOS}

Os autores agradecem a Coordenação de Aperfeiçoamento de Pessoal de Nível Superior (Capes) pela bolsa de doutorado pleno no exterior para o autor principal e pelo interesse no tema desenvolvido aqui.

\section{REFERÊNCIAS BIBLIOGRÁFICAS}

Agudelo-Vera, C. M., Leduc, W. R., Mels, A. R., \& Rijnaarts, H. H. (2012). Harvesting urban resources towards mroe resilient cities. Resource, Conservation and Recycling, 64, 3-12. doi:10.1016/j.resconrec.2012.01.014

Alberti, M., Marzluff, J. M., Shulenberger, E., Gordon, B., Ryan, C., \& Zumbrunnen, C. (2003). Integrating humans into ecology: Opportunities and challenges for studying urban ecosystems. Bioscience, 53(12), 1169-1179. doi: 10.1641/00063568(2003)053[1169:IHIEOA]2.0.CO

Association for the Study of Peak Oil USA. (2015). Oil Production by Country. Acesso em 22 de Junho de 2015, disponível em ASPO USA: http://peak-oil.org/peak-oil-reference/peak-oil-data/production-and-peak-dates-by-country/

Australian Government. (2013). Australia's whaling industry and whales. Acesso em 09 de Julho de 2015, disponível em Australia Government: http://www.australia.gov.au/about-australia/australian-story/australias-whaling-industry-andwhales

BP. (2013). BP Statistical Review of World Energy June 2013. BP. Fonte: http://www.bp.com/content/dam/bp/pdf/statisticalreview/statistical_review_of_world_energy_2013.pdf

BP. (2014). BP Energy Outlook 2035. BP. Fonte: http://www.bp.com/content/dam/bp/pdf/Energy-economics/EnergyOutlook/Energy_Outlook_2035_booklet.pdf

Castells, M. (1983). The City and the Grass-roots: Cross-Cultural Theory of Urban Social Movements. Berkeley: Univ. Calif. Press.

Castells, M. (2009). A Questao Urbana (4th ed.). Sao Paulo: Editora Paz e Terra S/A.

Collier, M. J., Nedović-Budić, Z., Aerts, J., Connop, S., Foley, D., Foley, K., Newport, D.; McQuaid, S.; Slaev, A., Verburg, P. (2013). Transitioning to resilience and sustainability in urban communities. Cities, 32(Supplement 1), s21-s28. doi:10.1016/j.cities.2013.03.010

Folke, C., Carpender, S. R., Walker, B., Scheffer, M., Chapin, T., \& Rockström, J. (2010). Resilience Thinking: Integrating Resilience, Adaptability and Transformability. Ecology \& Society, 15(4). Fonte: http://www.ecologyandsociety.org/vol15/iss4/art20/

Galderisi, A. (2014). Urban resilience: A framework for empowering cities in face of heterogeneous risk factors. ITU A/Z, 11(1), 36-58. Fonte: http://www.az.itu.edu.tr/azvol11no1web/06-Galderisi-1101.pdf

Gilbert, R., \& Perl, A. (2008). Transport Revolutions: Moving People and Freight without Oil. London: Earthscan.

Goldemberg, J., Johansson, T. B., Reddy, A. K., \& Williams, R. H. (1987). Energy for a Sustainable World. World Resource Institute. Fonte:

http://www.researchgate.net/profile/Thomas_Johansson2/publication/38994517_Energy_for_a_sustainable_world/links /540dc7da0cf2df04e75657fc.pdf

Hamilton, J. D. (2009). Causes and Consequences of the Oil Shock of 2007-08. Brookings Papers on Economic Activity, w15002, pp. 215-283. Fonte: http://www.brookings.edu/ /media/Projects/BPEA/Spring\%202009/2009a_bpea_hamilton.PDF

Hanson, S., \& Giuliano, G. (2004). The geography of urban transportation. Guilford Press.

Harvey, D. (2008). The Right to the City. New Left Review, 53, 23-40. Fonte: http://newleftreview.org/II/53/david-harvey-theright-to-the-city

Heinberg, R. (2003). The party's over: oil, war and the fate of industrial societies. Clairview books.

Hopkins, R. (2008). The transition handbook: from oil dependency to local resilience (eBook). Green books. Fonte: http://store.kobobooks.com/de-DE/ebook/the-transition-handbook-2

Hoyle, B., \& Knowles, R. (1998). Transport Geography: An Introduction. In B. Hoyle, \& R. Knowles, Modern Transport Geography (2nd ed., pp. 1-12). Wiley

IEA. (2015a). FAQs: Renewable energy. Fonte: http://www.iea.org/aboutus/faqs/renewableenergy/

IEA. (2015b). Spot Prices. Fonte:: http://www.eia.gov/dnav/pet/PET_PRI_SPT_S1_M.htm

IEEJ. (2013). Asia/World Energy Outlook 2013. Institute of Energy Economics of Japan (IEEJ). Fonte: https://eneken.ieej.or.jp/data/5331.pdf

Jabareen, Y. (2013). Planning the resilient city: Concepts and strategies for coping with climate change and environmental risk. Cities, 31, 220-229.

Leichenko, R. (2011). Climate change and urban resilience. Current Opinion in Environmental Sustainability, 3(3), 164-168. doi:10.1016/j.cosust.2010.12.014

Martin, S. (2001). The Whales' Journey. Allen \& Unwin.

Moore, M. (Director). (2004). Fahrenheit 9/11 [Motion Picture].

Nações Unidas. (2009). Human Security in Theory and Practice. United Nations. Fonte: http://www.tr.undp.org/content/dam/turkey/docs/news-from-new-horizons/issue-41/UNDP-TRHSHandbook_2009.pdf

Nações Unidas. (2015). World's population increasingly urban with more than half living in urban areas. Fonte:: http://www.un.org/en/development/desa/news/population/world-urbanization-prospects-2014.html 
Nef, J. U. (1977). An Early Energy Crisis and its Consequences. Scientific American, 140-150. Fonte: http://nature.berkeley.edu/er100/readings/Nef_1977.pdf

Newman, P., Beatley, T., \& Boyer, H. (2009). Resilient Cities: Responding to Peak Oil and Climate Change. Island Press.

OPEC. (2013). 2013 World Oil Outlook. Vienna: Organization of the Petroleum Exporting Countries (OPEC). Fonte: http://www.opec.org/opec_web/static_files_project/media/downloads/publications/W00_2013.pdf

Rodrigue, J. P., Comtois, C., \& Slack, B. (2013). The geography of transport systems. Routledge.

Sagan, S. D. (1979). Lessons of the Yom Kippur Alert. Foreign Policy, 36, pp. 160-177. Fonte: http://www.jstor.org/stable/1148213.

Schlör, H., Fischer, W., \& Hake, J. F. (2012). The meaning of energy systems for the genesis of the concept of sustainable development. Applied energy, 97, pp. 192-200.

Vale, L. J., \& Campanella, T. J. (2005). The resilient city: How modern cities recover from disaster. Oxford University Press.

Vasconcellos, E. A. (2014). Urban Transport Environment and Equity: The case for developing countries (eBook). Routledge. Fonte: http://store.kobobooks.com/de-DE/ebook/urban-transport-environment-and-equity

Wachs, M. (2004). Reflection on the Planning Process. In S. Hanson, \& G. Giuliano, The Geography of Urban Transportation (pp. 141-162). New York: The Guilford Press.

Wegener, M. (2004). Overview of Land-use Transport Models. In D. A. Hensher, K. J. Button, K. E. Haynes, \& S. Stopher, Handbook of Transport Geography and Spatial Systems, Volume 5 (Handbooks in Transport) (pp. 127-146). Emerald Group Publishing.

Winzer, C. (2012). Conceptualizing energy security. Energy Policy, 46, 36-48. doi:10.1016/j.enpol.2012.02.067

World Bank. (2015). GDP growth (annual \%). Acesso em 15 de Janeiro de 2015, disponível em The World Bank: http://data.worldbank.org/indicator/NY.GDP.MKTP.KD.ZG 